\title{
Closed Loop Speed Control Analysis of DC
}

\section{Motor}

\author{
Harshitha K T ${ }^{1}$, K.V.Shettigar ${ }^{2}$ \\ PG Scholar, EEE Department, NMAM IT, Nitte, India ${ }^{1}$ \\ Associate Professor, EEE Department, NMAM IT, Nitte, India ${ }^{2}$
}

\begin{abstract}
This paper presents the modeling and simulation of the DC Motor closed loop speed control. DC motors have large application area because of their robustness, speed and good load characteristics. Most of the application requires efficient speed control of DC motor. Here performance analysis of speed control of DC motor using PID controller and Fuzzy logic controller is carried out using MATLAB/SIMULINK. Using fuzzy, sensitiveness to variation of input torque and also any kind of system uncertainty can be overcome compared to all other conventional controllers. Finally fuzzy system can provide optimal performance and large range of speed control over the area.
\end{abstract}

Keywords: FLC, PID, DC Motor, speed control.

\section{INTRODUCTION}

Electrical motor systems are indispensable almost in every industry because of its good initializing and braking properties. Direct current motor has armature winding which is a single set of coils and another permanent magnet set called as stator of the motor. When coil is subjected to voltage in the magnetic field, a torque is generated which will results in the rotation of the motor. DC motors are found in many applications such as automotive system, automatic power drive control systems, robotics, home appliances, and industrial electronics especially in mining machines for rolling mills and in main hoist machines. All most in all the applications it requires precision positioning and controlling of the speed of the motor. Here voltage control method is used for controlling the speed of the motor. Average value applied to the DC motor is controlled by the DC chopper circuit act as driver circuit. Almost all the motor applications needs for a proper speed controller for its application. There are so many techniques are available for the speed control of the DC motor. This paper deals with the speed control of the DC motor by PID controller and FLC. In the PID controller proportional, derivative and integral constants of the PID are derived from the ZieglerNichols formula which is based on time responses and experiences. Whereas using fuzzy logic controller speed control is performed as per general behavior of the system.

\section{PMDC MOTOR MODELLING}

The mathematical modeling of the system is done on the actuation model of the PMDC motor shown in Fig. 1

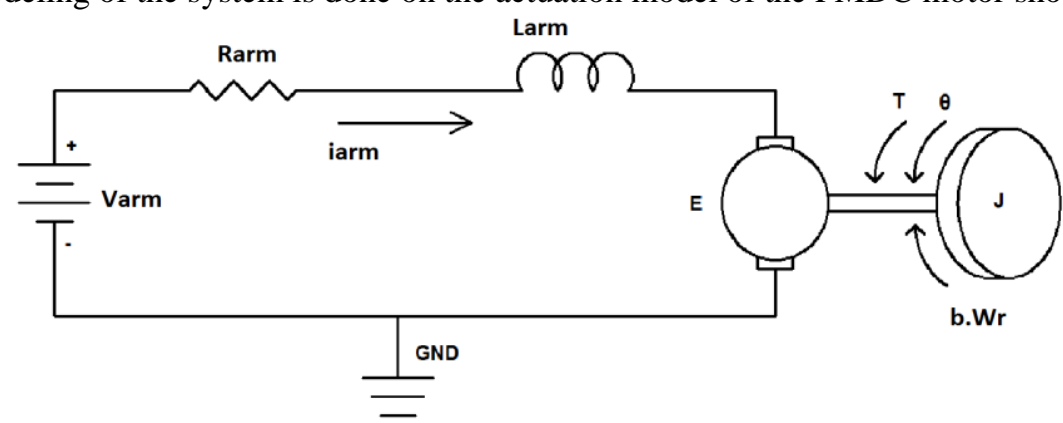

Figure 1: PMDC Motor Model

By applying Kirchhoff's voltage rule to the above circuit we will get

$$
\mathrm{V}_{\mathrm{arm}}=\mathrm{i}_{\mathrm{arm}} \cdot \mathrm{R}_{\mathrm{arm}}+\mathrm{L}_{\mathrm{arm}} \frac{\mathrm{di}_{\mathrm{arm}}}{\mathrm{dt}}+\mathrm{K}_{\mathrm{emf}} \cdot \mathrm{w}_{\mathrm{r}}
$$

Here $\mathrm{V}_{\text {arm }}$ is the applied voltage called as armature voltage. $i_{\text {arm }}$ is the current drawn by the motor. $R_{\text {arm }}$ and $L_{\text {arm }}$ are the armature Resistance and winding inductance of the DC motor. E is the back emf generated and is given by,

$$
\mathrm{E}=\mathrm{K}_{\mathrm{emf}} \cdot \mathrm{W}_{\mathrm{r}}
$$


$\mathrm{K}_{\mathrm{emf}}$, is a electrical constant.

Armature current equation is derived as

$$
\frac{\mathrm{di}_{\mathrm{arm}}}{\mathrm{dt}}=\frac{\mathrm{V}_{\mathrm{arm}}}{\mathrm{L}_{\mathrm{arm}}}-\mathrm{i}_{\mathrm{arm}} \cdot \frac{\mathrm{R}_{\mathrm{arm}}}{\mathrm{L}_{\mathrm{arm}}}-\frac{\mathrm{K}_{\mathrm{emf}}}{\mathrm{L}_{\mathrm{arm}}} \cdot \mathrm{w}_{\mathrm{r}}
$$

From the equation of motion,

$$
\mathrm{i}_{\mathrm{arm}}=\int \frac{\mathrm{V}_{\mathrm{arm}}-\mathrm{i}_{\mathrm{arm}} \cdot \mathrm{R}_{\mathrm{arm}}-\mathrm{K}_{\mathrm{emf}} \cdot \mathrm{w}_{\mathrm{r}}}{\mathrm{L}_{\mathrm{arm}}} \mathrm{dt} \text { (2) }
$$

For the rotary motion equation becomes,

$$
m . \ddot{x}+b \cdot \dot{x}+k \cdot x=f(t)
$$

$\mathrm{w}_{\mathrm{r}}$ is the angular velocity of the motor.

$$
\begin{aligned}
& \text { J. } \ddot{\theta}+b \dot{\theta}+\text { k. } \theta=T_{e} \\
& \text { J. } \ddot{\theta}+b \dot{\theta}+T_{l}=T_{e}
\end{aligned}
$$

By assuming shaft of the motor is rigid, we may neglect the stiffness parameter. In the equation $\mathrm{J}$ is motor inertia value, $\mathrm{b}$ indicates braking/damping coefficient. $\mathrm{T}_{\mathrm{e}}$ indicates the load torque applied to the motor, which is proportional to the current drawn by the motor and is given as,

$\mathrm{K}_{\mathrm{t}}$ is the torque constant of the motor.

$$
\mathrm{T}_{\mathrm{e}}=\mathrm{K}_{\mathrm{t}} \cdot \mathrm{i}_{\mathrm{arm}}
$$

Therefore speed equation is derived as,

$$
\mathrm{J} \dot{\mathrm{w}}_{\mathrm{r}}+\mathrm{b} \cdot \mathrm{w}_{\mathrm{r}}=\mathrm{K}_{\mathrm{t}} \cdot \mathrm{i}_{\mathrm{arm}}
$$

$$
\mathrm{w}_{\mathrm{r}}=\int \frac{\mathrm{T}_{\mathrm{e}}-\mathrm{bw}_{\mathrm{r}}-\mathrm{T}_{\mathrm{l}}}{\mathrm{J}} \mathrm{dt}
$$

From equation (1) and (2) ODE state space model can be written as,

$$
\left[\begin{array}{c}
\dot{w}_{\mathrm{r}} \\
i_{\mathrm{arm}}^{\cdot}
\end{array}\right]=\left[\begin{array}{cc}
-\mathrm{b} \backslash \mathrm{J} & \mathrm{K}_{\mathrm{t}} / \mathrm{J} \\
\frac{-\mathrm{K}_{\mathrm{emf}}}{\mathrm{L}_{\mathrm{arm}}} & \frac{-\mathrm{R}_{\mathrm{arm}}}{\mathrm{L}_{\mathrm{arm}}}
\end{array}\right]\left[\begin{array}{c}
\mathrm{w} \\
i_{\mathrm{arm}}
\end{array}\right]+\left[\begin{array}{c}
0 \\
1 / \mathrm{L}_{\mathrm{arm}}
\end{array}\right] \mathrm{V}_{\mathrm{arm}}
$$

From equation (2) and (4) we can model the PMDC motor for control application.

\section{Pid CONTROLLER}

Proportional-Integral-Derivative controllers are widely used in many of the control systems, where the number of control parameters to be tuned is less. In most of the control systems, control signals are proportional to the difference between the input signal and the feedback signal.

PID controller equation can be written as,

$$
Y(t)=K_{p}\left[e(t)+\frac{1}{T_{i}} \int_{0}^{t} e(\tau) d \tau+T_{d} \cdot \frac{d e(t)}{d t}\right]
$$

Where $Y(t)$ and $e(t)$ are control signal and error signals of the system to be controlled. $K_{p}, T_{i}$ and $T_{d}$ are the parameters to be controlled. the transfer function can be written as,

$$
\mathrm{K}(\mathrm{s})=\mathrm{K}_{\mathrm{P}}\left[1+\frac{1}{\mathrm{~T}_{\mathrm{i}}(\mathrm{s})}+\mathrm{T}_{\mathrm{d}}(\mathrm{s})\right]
$$

Main purpose of the PID controller is to adjust all the gain values so as to achieve optimum solution for control application. Fig. 4 shows the general diagram of the PID controller.

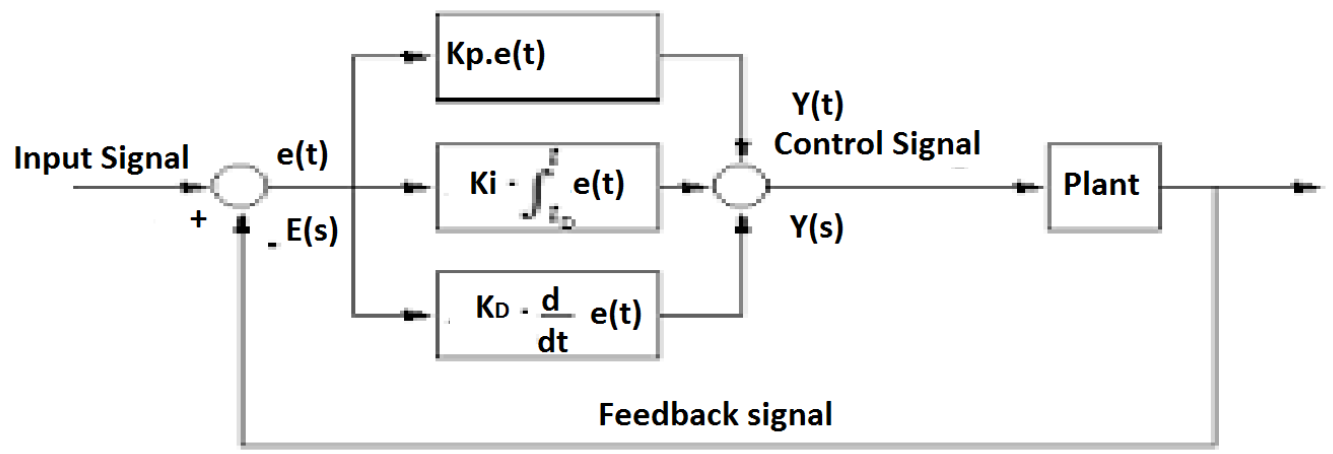

Figure 4: General block diagram of PID Controller.

The transfer function can be written as 


$$
\frac{\mathrm{Y}(\mathrm{S})}{\mathrm{E}(\mathrm{S})}=\mathrm{K}_{\mathrm{P}}+\frac{\mathrm{K}_{\mathrm{i}}}{\mathrm{S}}+\mathrm{K}_{\mathrm{D}} \mathrm{S}
$$

For tuning the system it requires the transfer function of the system. Transfer function can be written as

The standard form of the system can be written as,

$$
G(S)=\frac{0.8}{0.0501 S^{3}+8.3500 S^{2}+0.6483 S}
$$

$$
\mathrm{G}(\mathrm{S})=\frac{\mathrm{K}}{\mathrm{n}_{3} \mathrm{~S}^{3}+\mathrm{n}_{2} \mathrm{~S}^{2}+\mathrm{n}_{1} \mathrm{~S}}
$$

Where, $n_{3}=\mathrm{L}_{\text {arm }} \cdot J, \mathrm{n}_{2}=\mathrm{R}_{\mathrm{arm}} \cdot \mathrm{J}+\mathrm{L}_{\mathrm{arm}} \cdot \mathrm{b}, \mathrm{n}_{1}=\mathrm{K}_{\mathrm{emf}} \cdot \mathrm{K}_{\mathrm{t}}+\mathrm{R}_{\mathrm{arm}} \cdot \mathrm{b}$.

Overall transfer function of the entire system can be written as

The pole locations are found from

$$
\mathrm{T}(\mathrm{S})=\frac{\mathrm{K}\left(\mathrm{K}_{\mathrm{D}} \mathrm{S}^{2}+\mathrm{K}_{\mathrm{P}} \mathrm{S}+\mathrm{K}_{\mathrm{t}}\right)}{\mathrm{n}_{3} \mathrm{~S}^{4}+\mathrm{n}_{2} \mathrm{~S}^{3}+\left(\mathrm{n}_{1}+\mathrm{K}_{\mathrm{D}} \mathrm{K}\right) \mathrm{S}^{2}+\mathrm{K}_{\mathrm{P}} \mathrm{K} \mathrm{S}+\mathrm{K}_{\mathrm{i}} \mathrm{K}}
$$

But the actual pole locations are the roots of

$$
\mathrm{n}_{3} \mathrm{~S}^{4}+\mathrm{n}_{2} \mathrm{~S}^{3}+\left(\mathrm{n}_{1}+\mathrm{K}_{\mathrm{D}} \mathrm{K}\right) \mathrm{S}^{2}+\mathrm{K}_{\mathrm{P}} \mathrm{K} \mathrm{S}+\mathrm{K}_{\mathrm{i}} \mathrm{K}=0
$$

$$
\left(S^{2}+2 S \delta w_{n} S+w_{n}^{2}\right)\left(K_{D} K S^{2}+K_{P} K S+K_{i} K\right)=0
$$

By comparing (5) and (6) $\mathrm{K}_{\mathrm{P}}, \mathrm{K}_{\mathrm{i}}$ and $\mathrm{K}_{\mathrm{D}}$ are derived. For the proper tuning Zeigler-Nichols method is used. By increasing $K_{P}$ value from 0 to critical value sustained oscillations are achieved.

\section{FUZZY LOGIC CONTROLLER}

The controlling action using fuzzy can be done as per human opinion and perceptions. All most all the control mechanisms depend on the exactness of the system modeling and parameters of the system but FLC will depend on the different strategies of the motor control. and it will not offer for a exact system model because FLC system is based on linguistic variable definition and experiences rather than system model The general block diagram of FLC is shown in Fig.5. FLC consists of four main components,

A. Fuzzification

It will generate the linguistic variable from the input crisp value using fuzzy reasoning mechanism.

$B$. Knowledge base

It includes all the linguistic variables definition.

C. Fuzzy reasoning mechanism

It will perform actual fuzzy logic operation by using all input values and perform appropriate control action.

D. Defuzzification

It will convert the result back to output crisp.

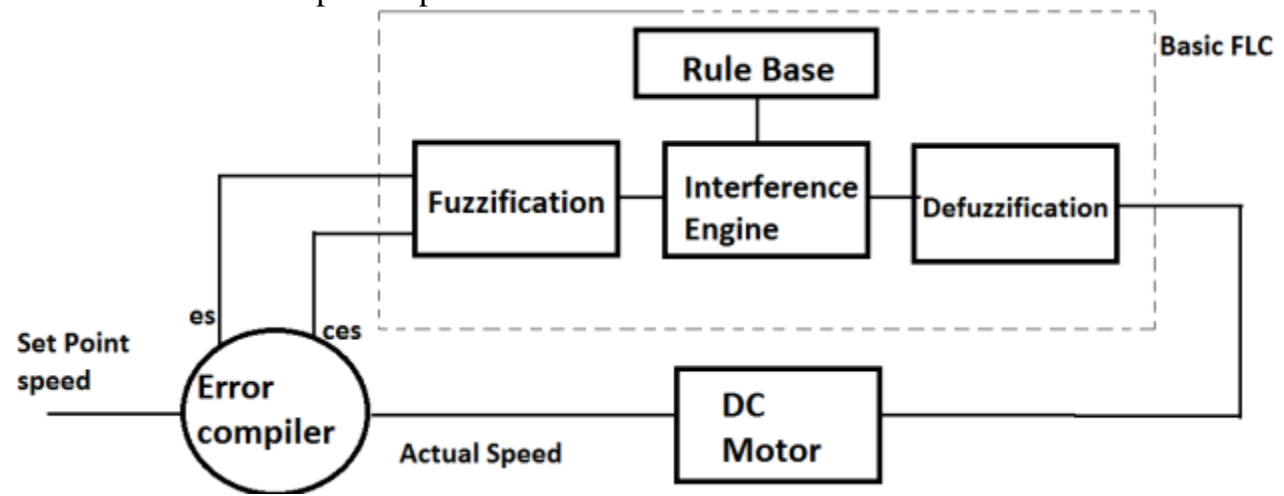

Figure 5: Basic FLC Diagram.

Present FLC consist of two input variables and one output variable with seven linguistic variable in each. All the variables are involved in decision making and is based on simple IF THEN rules defined by the transformation matrix of the FAM.

Defuzzification, used here is a Centroid defuzzification which will calculates the area under the aggregated output, which will results into a single output crisp and is applied to the system for control action. The surface diagram of the FLC Designed is as shown in Fig.6. 


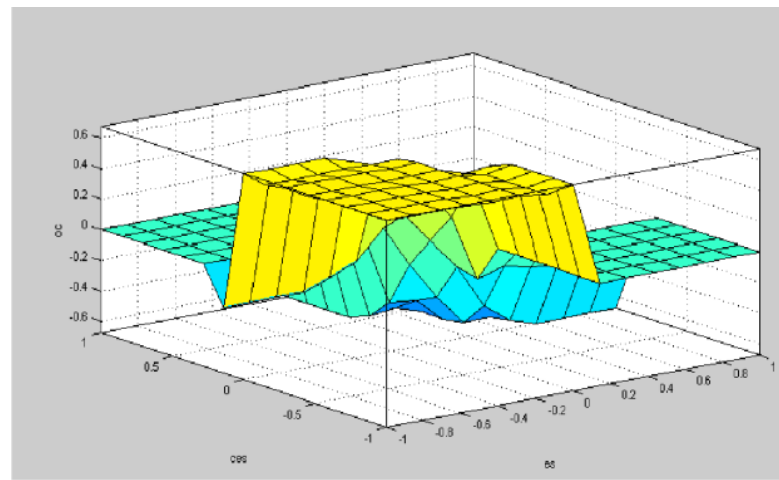

Figure 6: Surface diagram of FLC design.

IV. SIMULATION RESULTS

The full DC motor speed control scheme was digitally simulated using MATLAB/SIMULINK Fig.7 indicates the DC motor Modeling derived from equation (2) and (4).

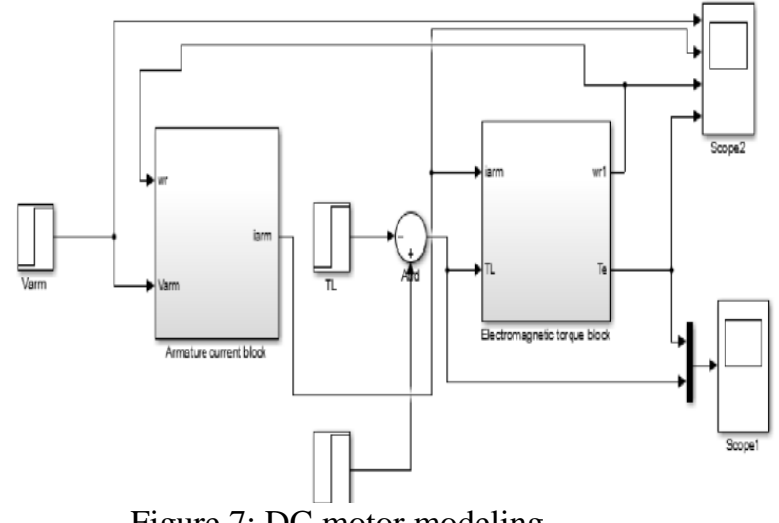

Figure 7: DC motor modeling

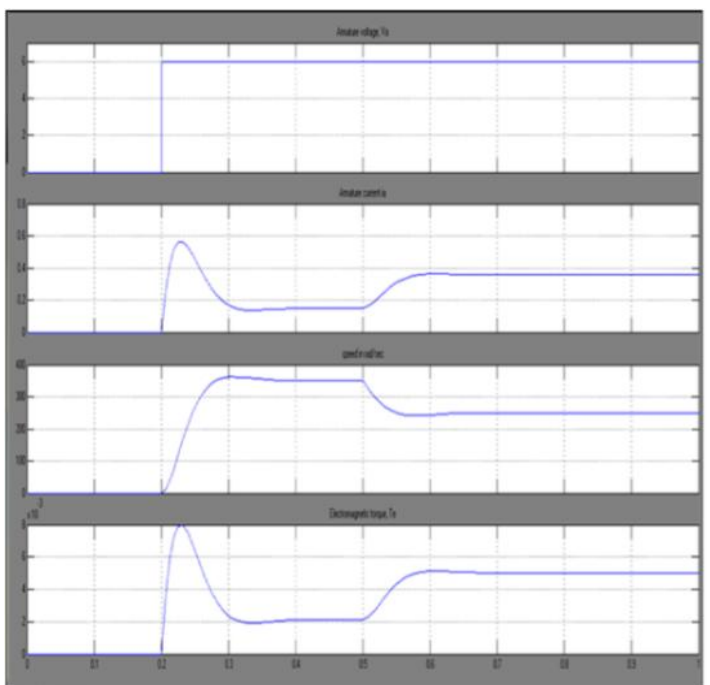

Figure 8: DC Motor waveforms

Fig.8 shows the waveforms of the DC motor. Initially there is no speed control is employed.The speed control of the DC motor is carried by two control strategies

A.PID controller

Fig.9 shows the SIMULINK block of the Speed control of the DC motor with PID controller Fig.10 shows the controlled speed of the DC motor

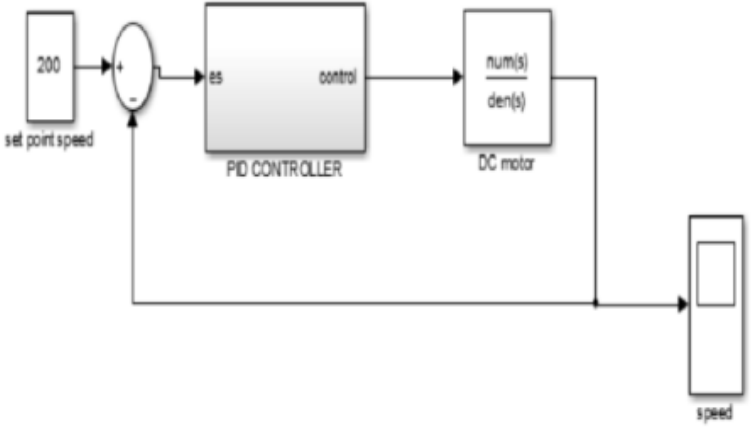

Figure.9: PID controller for DC motor.

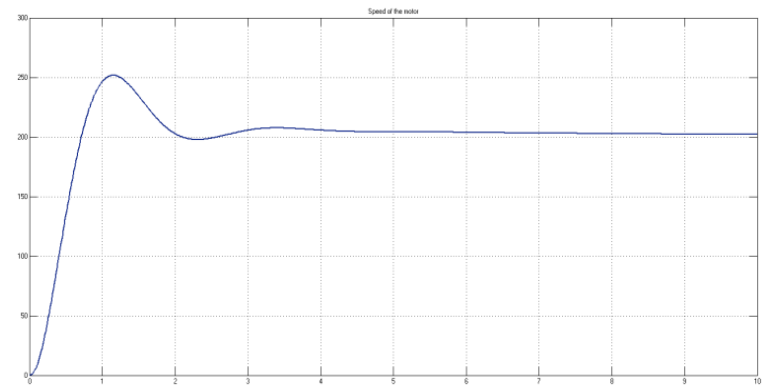

Figure.10: Controlled speed Output of DC motor.

B .Fuzzy logic controller

Fig.11 shows the SIMULINK block diagram of speed control of the dc motor with FLC. Fig.12 displays the controlled speed waveform of the system. 
Vol. 4, Special Issue 2, April 2016
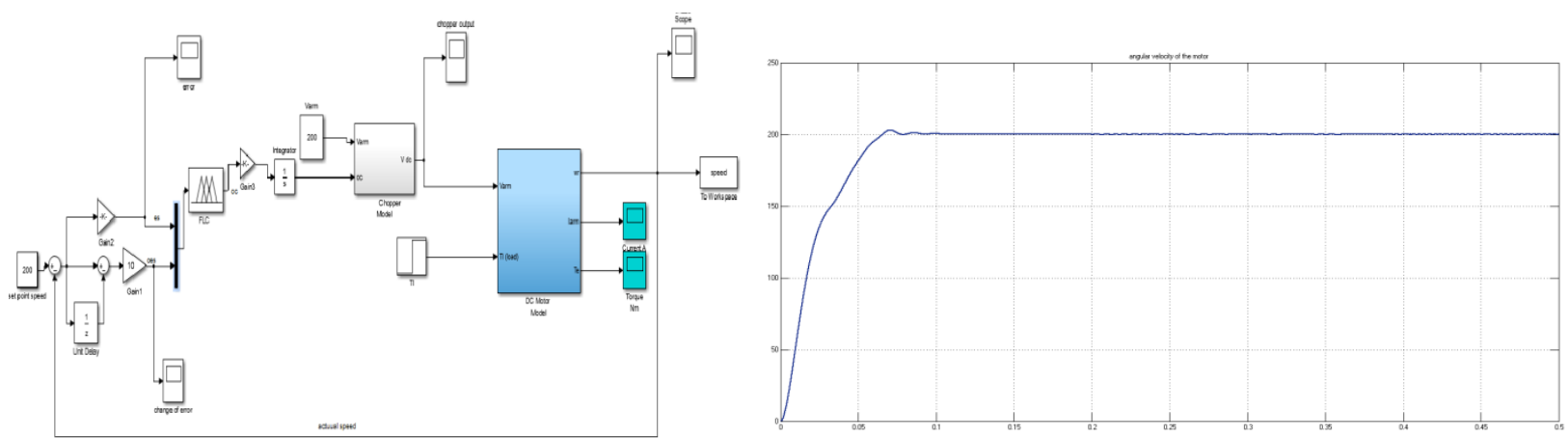

Figure.11: SIMULINK Block diagram of FLC

Figure 12.Controlled speed waveform of DC motor with FLC

\section{CONCLUSION}

The speed control of DC motor is simulated in MATLAB/SIMULINK environment. DC motor speed control is done using PID controller and FLC. Simulation results infers that FLC has less steady state error, overshoot, settling time and rise time compared to PID controller. FLC will respond better for load disturbances and varying inputs .Other than this FLC will give the wide operating area and always produce reasonable results. Using FLC we can acquire fast response even when load is continuously changing.

\section{REFERENCES}

[1]. R.Krishnan, Electric Motor Drives Modelling, Ananlysis and Control, original ed., Virginia Tech,Blacksburg,VA 2001

[2]. Prof. Aziz Ahmed, Yogesh Mohan, Aasha Chauhan, Pradeep Sharma Comparative Study of Speed Control of D.C.Motor Using PI, IP, and Fuzzy Controller International Journal of Advanced Research in Computer and Communication Engineering Vol. 2, Issue 7, July 2013

[3]. Miguel Angel Sorelo and Jose E. Naranjo Vision-based Adaptive Cruise Control for Intelligent Road Vehicles Proceedings of 2004 1EEEIRS.J International Conference on Intelligent Robots and Systems,pp 64-69, September 28 -October 2,2004, Sendai, Japan

[4]. P. M. Meshram and Rohit G. Kanojiya Tuning of PID Controller using Ziegler- Nichols Method for Speed Control of DC Motor IEEEInternational Conference On Advances In Engineering, Science And Management,pp117-122, (ICAESM -2012) March 30, 31,2012

\section{BIOGRAPHIES}

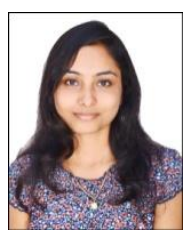

Harshitha K T, received her B.E. (E\&C) degree from Kurunji Venkatramana College of Engineering, Sullia, India in 2014. Pursuing M.Tech.(Microelectronics and Control Systems) in Nitte Mahalinga Adyanthaya Memorial Institute of Technology, Nitte, Karkala, India. Her area of interest includes DC Machines and Embedded systems.

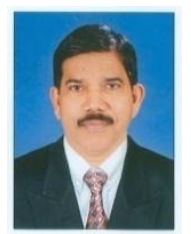

K. Vasudeva Shettigar, received his B.E. (E \& E) degree from SJCE, Mysore University, Mysore, India in 1986, and M.Tech. (Power Systems) degree in 1992 from National Institute of Engineering affiliated to Mysore University. Presently Mr. Vasudeva Shettigar is serving as Associate Professor, Dept. of Electrical \& Electronics Engineering, Nitte Mahalinga Adyanthaya Memorial Institute of Technology, Nitte, Karkala, India. He is Life member of ISTE. He has published 10 technical research papers in various National and International conferences. He has chaired International conference held at NMAMIT Nitte during May 2011, 2013 and 2015. Mr. Shettigar has organized several National Conferences and National Workshops and Short term training programmes (STTP) in the college for the benefit of faculty (NMAMIT) and faculty of neighbouring Institutes. His areas of interest include power system \& protection, power quality and High Voltage Engineering. He has a teaching experience of over 27 Years, and guided over 50 U.G \& 24 P.G. Technical Project works. 